\title{
MICROWAVE HALL MOBILITY AND CONDUCTIVITY IN CRYSTALS OF VARIOUS (BEDT-TTF) RADICAL SALTS
}

\author{
M. DRESSEL ${ }^{*}$ and H.W. HELBERG \\ Drittes Physikalisches Institut der Universität Göttingen, Göttingen (F.R.G.) \\ D. SCHWEITZER \\ Drittes Physikalisches Institut der Universität Stuttgart, Stuttgart (F.R.G.)
}

\begin{abstract}
We report investigations of the microwave transport properties carried out on the organic conductors and superconductors of (BEDT-TTF)-salts: $\alpha-, \alpha_{t}-$ and $\beta-(B E D T-T T F)_{2} I_{3}$, $\alpha-(\mathrm{BEDT}-\mathrm{TTF})_{3}\left(\mathrm{NO}_{3}\right)_{2}$ and $x-(\mathrm{BEDT}-\mathrm{TTF})_{2} \mathrm{Cu}(\mathrm{NCS})_{2}$. The anisotropy and temperature dependence $(300 \mathrm{~K}$ to $4 \mathrm{~K})$ of the high-frequency conductivity was measured in a microwave cavity at $10.3 \mathrm{GHz}$. There is low anisotropy in the high conducting plane of the quasi two-dimensional crystals of the (BEDT-TTF)-family, e.g. the $(\vec{a}, \vec{b})$-plane in $\beta-(B E D T-T T F)_{2} l_{3}$; perpendicular to this the microwave conductivity is one order of magnitude lower. At room temperature the microwave Hall mobility at $9.5 \mathrm{GHz}$ of the different phases of (BEDT-TTF) $\mathrm{l}_{3}$ and (BEDTTTF $)_{3}\left(\mathrm{NO}_{3}\right)_{2}$ is 100 to $200 \mathrm{~cm}^{2} / \mathrm{Vs}$ in the high conducting planes of the crystals. With about $1200 \mathrm{~cm}^{2} / \mathrm{Vs}$ the high-frequency mobility of the superconductor (BEDT-TTF) ${ }_{2} \mathrm{Cu}(\mathrm{NCS})_{2}$ is similar to the one measured in the $(\vec{a}, \vec{b})$-plane of the high- $T_{c}$ superconductor $\mathrm{YBa}_{2} \mathrm{Cu}_{3} \mathrm{O}_{7}$.
\end{abstract}

\section{INTRODUCTION}

Due to small size and uncertainty of the contact resistance at single crystals of bis (ethylenedithio)tetrathiafulvalene (BEDT-TTF) radical salts the dc-Hall measurements are very difficult $[1,2]$. Contactless high-frequency methods for studying the bulk transport properties of (BEDT-TTF) crystals were used to avoid the problems affected by various surface effects: the cavity perturbation technique for measuring the ac-conductivity and bimodal cavities suitable for the determination of the Hall mobility in very small crystals.

\section{EXPERIMENTAL TECHNIQUES}

All microwave investigations were performed at small crystalline samples (e.g. $1 \mathrm{~mm} \times$ $0.05 \mathrm{~mm}$ ). The samples were placed in the centre of a cylindrical cavity working in the $\mathrm{TE}_{111}$ or $\mathrm{TM}_{\mathrm{O} 10^{-}}$-mode at $10.3 \mathrm{GHz}$ for conductivity measurements. The complex permittivity $\varepsilon=\varepsilon^{*}-i \varepsilon^{*}$ and thus the conductivity $\sigma$ is determined from the frequency shift and the change of the quality factor, using the well-known cavity perturbation technique [3].

In order to measure the microwave Hall mobility $\mu_{H}$ we used bimodal cavities of different shape, size and frequency [4], e.g. a cylindrical $\mathrm{TE}_{112}$-cavity for $9.5 \mathrm{GHz}$, similar to the one described by Ong, Bauhofer and Wei [5]. Iris coupling of two orthogonal waveguides was chosen instead of probe coupling [6] for greater mechanical stability. In one antinode of the orthogo-

- Present address: Laser-Laboratorium Göttingen, Im Hassel 21, D-3400 Gottingen, F.R.G. 
nal electric fields a flat sample was placed in such a way as to allow the current paths to be in the sample plane. With the help of four tuning probes and two iris tuner we were able to obtain a mode seperation of $65 \mathrm{~dB}$ up to $80 \mathrm{~dB}$ depending on the shape of the sample. The procedure of balancing the cavity is described in Ref. [4 - 7]. Using a bucking channel (1) as shown in Fig. 1 the remaining non-ideal output signal could be cancelled below the apparatus limit $(-100 \mathrm{dBm})$ of the superheterodyne receiver (SR). For keeping the shf-generator (G) precisely at the resonant frequency of the cavity a special frequency control (FC) was used. After tuning the cavity the degeneration of the two modes was better than $200 \mathrm{kHz}$. The static magnetic field ( $B \leq 1$ Tesla) was applied normal to the sample surface. i.e. parallel to the axis of the cavity, and induced a rotation of the current paths in the sample by the Hall angle $\arctan \left(\mu_{H} B\right)$. The analysis of the dual mode cavity by a scattering matrix $S[4,6,8]$ leads to

$$
\tan \vartheta_{H}=\mu_{H} B=\frac{-1}{f(S)_{g}(S)} \sqrt{\frac{P_{0}}{P_{1}}} \text {. }
$$

with $P_{1}$ and $P_{0}$ the input power, resp. output power; $f(S)$ is a function of the permittivity $\varepsilon^{*}: E^{-}$ and the depolarization factor $N$ of the sample and becomes exactly 1 for low conductivity and $f(S)=-1$ for high conductivity [4.9]: $\left.N \varepsilon^{\prime \prime} * 1+M \varepsilon^{\circ}-1\right)$. By measuring the reflection coefficient of the loaded cavity at each waveguide $\left(\Gamma_{S}\right.$, resp. $\left.\Gamma_{S 2}\right)$ and the quality $Q_{s}$ and $Q_{0}$ of the loaded and unloaded cavity the factor $g(S)$ can be determined in the symmetrical case $[4,6,8]$ :

$$
g(S)=\left(1-\frac{Q_{S}}{Q_{0}}\right) \sqrt{\left(1-\Gamma_{S_{1}}\right)\left(1-\Gamma_{S_{2}}\right)}
$$

The transmitted signal is proportional to $\mu_{H} B$ for weak magnetic field $[6,8,10]$. It could be determined by using a variable calibrated attentuator (PA1) and a phase shifter (P) for zero adjustment. The apparatus was tested with $p-G a A s$ and the accuracy is about 20\%. A detailed discussion of the experimental errors and accuracy can be found in Ref. [4. 11]. The influence of the depolarization factor [4, 9], the Hall effect in the cavity walls (Lorentz force on the wall current ) [11 - 12] and the effects of the second and third order in $B$ (e.g. influence of the magnetoresistance) [8] were taken into account in the advanced data analysis [4].

\section{RESULTS AND DISCUSSION}

Above the phase transition at $T_{\mathrm{MI}}=135 \mathrm{~K}$ the microwave conductivity of $\alpha-(\mathrm{BEDT}-T \mathrm{TF})_{2} \mathrm{I}_{3}$ is rather constant and isotropic with a room temperature value of $30(\Omega \mathrm{cm})^{-1}$ in the high con-

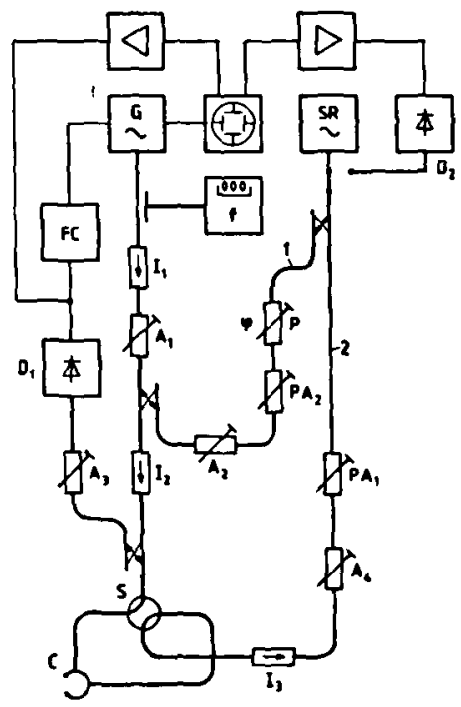

$\begin{array}{ll}\text { 1 } & \text { bucking and reference arm } \\ 2 & \text { main channel } \\ \text { G } & \text { microwave generator } \\ \text { f frequency counter } \\ \text { FC frequency control } \\ \text { SR superheterodyne receiver } \\ \text { D microwave diode } \\ \text { I isolator } \\ \text { A variable attenuator } \\ \text { PA calibrated precision attenuator } \\ \text { P variable phase shifter } \\ \text { S waveguide switch } \\ \text { C bimodal cavity }\end{array}$

Fig. 1. Block diagram of the miocrowave circuit used for the dual mode cavity 
ducting $(\vec{a}, \vec{b})$-plane [13]. Tempering a sample for a few days at $70^{\circ} \mathrm{C}$ it undergoes a transition to the superconducting $\alpha_{t}$-phase $\left(T_{c}=8 \mathrm{~K}\right)$ [14]. In $\alpha_{t}$-(BEDT-TTF) ${ }_{2} I_{3}$ the metal-isolator transition is suppressed and the conductivity is quite constant down to $4 \mathrm{~K}$ (Fig. 2). The microwave conductivity at $10.3 \mathrm{GHz}$ in the $(\vec{a}, \vec{b})$-plane of the former $\alpha$-phase is about $20(\Omega \mathrm{cm})^{-1}$ at room temperature. The related $\beta$-modification undergoes a number of phase transitions and subphases between 300 and $4 \mathrm{~K}$. Different $\beta$-(BEDT-TTF $)_{2} I_{3}$-crystals show no unique temperature behaviour of the microwave conductivity, depending on the crystal quality and history. The typical anisotropy of the high-frequency conductivity is shown in Fig. 3: $\sigma_{\mathrm{ab}} / \sigma_{\mathrm{c}}=70$.

In the crystals of (BEDT-TTF) ${ }_{2} \mathrm{I}_{3}$ we found no significant magnetoresistance in the whole temperature range from $300 \mathrm{~K}$ down to $4 \mathrm{~K}$ and for an applied magnetic field up to 1 Tesla. The maximum value for the magnetoresistance of $\alpha-(B E D T-T T F)_{2} I_{3}$ reported by Pokhodyna et. al. [1], is about two orders of magnitude below our apparatus limit of $\frac{\Delta p}{p}=10^{-2}$.

Investigations of the microwave Hall mobility could only be carried out at room temperature. The results for different crystals and orientations are listed in Table 1. The high-frequency Hall mobility is about $200 \mathrm{~cm}^{2} /$ S for all modifications of (BEDT-TTF) ${ }_{2} \mathrm{I}_{3}$. The carrier mobility of $\alpha_{t}$-(BEDT-TTF) ${ }_{2} I_{3}$ might be affected by grain boundaries and remaining areas of the original $\alpha$-phase. Assuming just one kind of charge carriers in $\alpha$-(BEDT-TTF) ${ }_{2} I_{3}$ the Hall coefficient at room temperature would be estimated to $R_{H}=\sigma / \mu_{H}=8 \cdot 10^{-6} \mathrm{~m}^{3} /$ As and the charge carrier concentration $n=\sigma / \mu_{H} e=1 \cdot 10^{18} \mathrm{~cm}^{-3}$. in contrast to optical studies [15] and thermoelectric measurements [13]. Therefore the high-frequency results can not be explained by a simple model with extended states-charge carriers. Our experimental data confirm the assumption of the existence of additional charge charriers generated by a narrow band near the Fermi level. These states were postulated by calculations of the electronic band structure [16]. They have to be characterized by low charge carrier density and high mobility.

In (BEDT-TTF) ${ }_{3}\left(\mathrm{NO}_{3}\right)_{2}$ the hf-conductivity is ranging from 100 to $350(\Omega \mathrm{cm})^{-1}$, depending on the quality of the crystals. The results for the Hall mobility $\mu_{H}(T=300 \mathrm{~K})=120 \mathrm{~cm}^{2} / \mathrm{Vs}$ and the carrier concentration $n=2 \cdot 10^{19} \mathrm{~cm}^{-3}$ are in good agreement with the characterisation as a semiconductor. The large mobility $1200 \mathrm{~cm}^{2} / \mathrm{Vs}$ in $(\mathrm{BEDT}-\mathrm{TTF})_{2} \mathrm{Cu}(\mathrm{NCS})_{2}$ corresponds to a high microwave conductivity of about $400(\Omega \mathrm{cm})^{-1}$ at $300 \mathrm{~K}$. In crystals of the high- $T_{c}$ superconductor $\mathrm{YBa}_{2} \mathrm{Cu}_{3} \mathrm{O}_{7}$ values of the same order were measured: $\mu_{H}=1900 \mathrm{~cm}^{2} / \mathrm{Vs}$.

The high-frequency measurements have to be continued in order to get a better character-

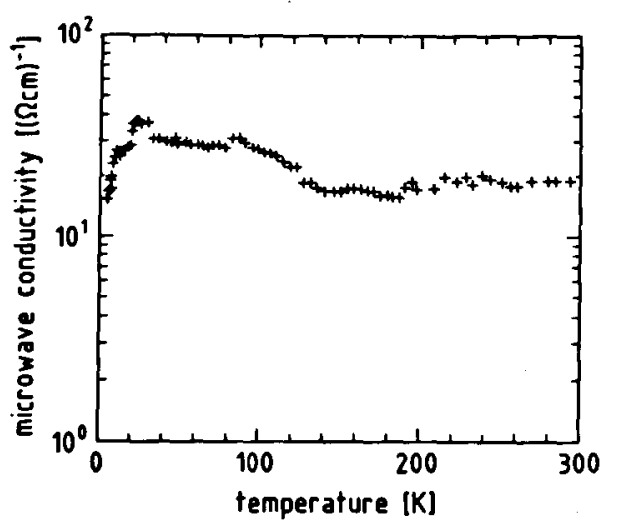

Fig. 2. Temperature dependence of the microwave conductivity of $\alpha_{t}$ - (BEDTTTF) ${ }_{2} I_{3}$ measured at a frequency of 10.3 $\mathrm{GHz}$ in the $(\vec{a}, \vec{b})$-plane of the former $\alpha$-phase

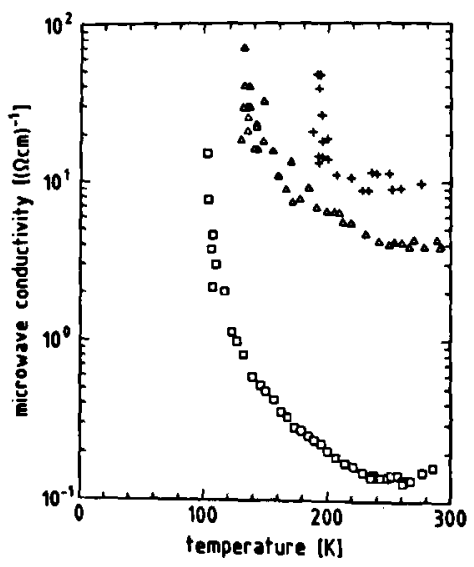

Fig. 3. Microwave conductivity at 10.3 GHz in a single $\beta$-(BEDT-TTF) ${ }_{2} \mathrm{I}_{3}$-crystal vesus temperature for three crystal directions : $(+)$ in the $(\vec{a}, \vec{b})$-plane perpendicular to the chain: $(\Delta)$ parallel to the chain; (D) normal to the $(\vec{a}, \vec{b})$-plane 
TABLE 1

Microwave Hall mobility measured in a bimodal cavity at $9.5 \mathrm{GHz}$ and $300 \mathrm{~K}$ for different samples and crystal orientations with an applied magnetic field $B$ up to 0.8 Tesla.

\begin{tabular}{|c|c|c|c|}
\hline Crystal & $\begin{array}{l}\text { Microwave } \\
\text { Hall mobility }\end{array}$ & \begin{tabular}{|} 
Orientation of \\
the electrical field
\end{tabular} & $\begin{array}{c}\text { Orientation of } \\
\text { the magnetic field }\end{array}$ \\
\hline$\overline{\alpha-(B E D T-T T F)_{2} I_{3}}$ & $250 \mathrm{~cm}^{2} / \mathrm{Vs}$ & in $(\vec{a}, \vec{b})$-plane & $\overline{\mathbf{B}} \| \overrightarrow{\mathrm{c}}$ \\
\hline$\beta-(B E D T-T T F)_{2} I_{3}$ & $\begin{array}{l}200 \mathrm{~cm}^{2} / \mathrm{Vs} \\
160 \mathrm{~cm}^{2} / \mathrm{Vs}\end{array}$ & $\begin{array}{l}\text { in }(\vec{a}, \vec{b}) \text {-plane } \\
\text { in }\left(\vec{a}, \vec{c}^{*}\right) \text {-plane }\end{array}$ & $\begin{array}{l}\vec{B} \| \vec{c} \\
\vec{B} \text { in }(001) \perp \vec{a}\end{array}$ \\
\hline$\alpha_{t}-(B E D T-T T F)_{2} I_{3}$ & $100-230 \mathrm{~cm}^{2} / \mathrm{Vs}$ & $\begin{array}{l}\text { in }(\vec{a}, \vec{b}) \text {-plane } \\
\text { of the origin }\end{array}$ & $\begin{array}{r}\vec{B} \| \overrightarrow{\vec{C}^{*}} \\
\text { al } \alpha \text {-phase }\end{array}$ \\
\hline$\alpha-(\mathrm{BEDT}-\mathrm{TTF})_{3}\left(\mathrm{NO}_{3}\right)_{2}$ & $120 \mathrm{~cm}^{2} / \mathrm{Vs}$ & in $(\vec{a}, \vec{c})$-plane & $\vec{B} \| \vec{b}$ \\
\hline$x-(\mathrm{BEDT}-\mathrm{TTF})_{2} \mathrm{Cu}(\mathrm{NCS})_{2}$ & $1200 \mathrm{~cm}^{2} / \mathrm{Vs}_{\mathrm{s}}$ & In $(\vec{b}, \vec{c})$-plane & $\overrightarrow{\mathbf{B}} \| \overrightarrow{\mathbf{a}} \cdot$ \\
\hline $\mathrm{YBa}_{2} \mathrm{Cu}_{3} \mathrm{O}_{7}$ & $1900 \mathrm{~cm}^{2} / \mathrm{Vs}$ & in $(\vec{a} \cdot \vec{b})$-plane & $\vec{B} \| \vec{C}$ \\
\hline
\end{tabular}

ization of these materials. At the present stage it is difficult to find a quantitative description of the observed phenomena. For the definitive answer the frequency dependent conductivity and temperature dependent microwave Hall mobility measurements are planned.

\section{ACKNOWLEDGEMENTS}

This work has been supported by the Stiftung Volkswagenwerk. We thank $K$. Winzer for the $\mathrm{YBa}_{2} \mathrm{Cu}_{3} \mathrm{O}_{7}$-crystals. The study of $\mathrm{YBa}_{2} \mathrm{Cu}_{3} \mathrm{O}_{7}$ was part of the Göttinger HTSL-Forschungsverbund and supported by Grant No. 13 N5493 from the BMFT.

\section{REFERENCES}

1 K.I Pokhodnya, Yu.V. Sushko, M.A. Tanatar, Sov. Phys. JETP 65 (1987) 795

2 K. Murata, M. Ishibashi, Y. Honda, M. Tokumoto, N. Kinoshita, H. Anzai, L. Phys. Soc. Japan 58 (1989) 3469

3 H.W. Helberg, B. Wartenberg, Z. angew. Phys. 20 (1966) 505; H. Schäfer. Ph.D. Thesis. Göttingen, F.R.G., 1983

4 M. Dressel, Ph.D. Thesis, Göttingen, F.R.G., 1989

$5 \quad$ N.P. Ong, W. Bauhofer, C.-J. Wei, Rev. Sci. Instr. 52 (1981) 1367

6 M.M. Sayed, C.R. Westgate, Rev. Sci. Instr. 46 (1975) 1074 and 1080

7 D.W. Griffin, Brit. J. Appl. Phys. 18 (1967) 1743

8 N. Watanabe, Rev. Electr. Commun. Lab. 8 (1960) 256

9 R.H. Caverly, I. Appl. Phys. 58 (1985) 3124

10 K. Yamagata, Sci. Rep. Res. Inst. Tohuku Univ. A12 (1960) 235; S.H. Liu. Y. Nishina, R.H. Good Jr., Rev. Sci. Instr. 32 (1961) 784; E.M. Trukhan, Instr. Exper. Techn. 1 (1965) 946;

D.D. Eley, R. Pethig, Disc. Faraday Soc. 51 (1971) 164

11 D.D. Eley, N.C. Lockhart, J. Phys. E: Sci. Instr. 16 (1983) 47

12 E.M. Trukhan, Radio Engin. Electr. Phys. 11 (1966) 1097: J.R. Fletcher, J. Phys. E: Sci. Instr. $\underline{9}$ (1976) 481

13 K. Bender, K. Dietz, H. Endres, H.W. Helberg, I. Henning, H.J. Keller, H.W. Schäfer. D. Schweitzer, Mol. Cryst. Liq. Cryst. 107 (1984) 45

14 D. Schweitzer, P. Bele, H. Brunner, E. Gogu, U. Haeberlen, I. Hennig, I. Klutz, R. Swietlik. H.J. Keller, Z. Phys. B: Cond. Matter 67 (1987) 489

15 B. Koch, H.P. Geserich, W. Ruppel, D. Schweitzer, K.H. Dietz, H.J. Keller, Mol. Cryst. Liq. Cryst. 119 (1985) 343

16 J. Kiubler, M. Weger, C.B. Sommers, Solid State Commun, 62 (1987) 801: M. Weger. K. Bender, T. Klutz, D. Schweitzer, F. Gross, C.P. Heidmann, Ch. Probst, K. Andres, Synthetic Metals 25 (1988) 49 